\title{
The Role of MicroRNA in Hepatitis C Virus Replication
}

\author{
Xiao-Qiong Duan ${ }^{1}$, Shi-Lin $\mathrm{Li}^{1}$, Yu-Jia Li ${ }^{1}$, Bing Liu ${ }^{1}$, Pei-Bing Zeng ${ }^{1}$, Chun-Hui Yang ${ }^{1}$ and \\ Li-Min Chen ${ }^{1,2}$ \\ ${ }^{1}$ Institute of Blood Transfusion, Chinese Academy of Medical Sciences and Peking Union Medical College, Chengdu, Sichuan, \\ China; ${ }^{2}$ Toronto General Research Institute, University of Toronto, Toronto, ON, Canada
}

\begin{abstract}
Hepatitis C virus (HCV) infection is a major global health problem. There is no effective vaccine and the current treatment regimen with pegylated interferon $\alpha$ and ribavirin is associated with significant adverse events. Therefore, there is an urgent need to identify new antiviral targets for HCV therapy. In recent years, a growing number of microRNAs (miRNAs) have been reported to be able to regulate $\mathrm{HCV}$ replication and infection by interacting with the HCV genome directly or by regulating host innate immunity to build a nonspecific antiviral state within cells. In this review, we discuss HCV virology and standard of care followed by miRNA in general, and then give a brief overview of miRNAs involved in HCV infection and discuss their potential application as a therapeutic option for the treatment of HCV infection.

(C) 2013 The Second Affiliated Hospital of Chongqing Medical University. Published by XIA \& HE Publishing Ltd. All rights reserved.
\end{abstract}

\section{HCV: virology and treatment}

Hepatitis C virus (HCV) is a small, hepatotropic, positivestrand RNA virus with a genome of approximately $9.6 \mathrm{~kb}$ in length. ${ }^{1,2}$ The HCV genome consists of a single open reading frame that encodes viral proteins and a $5^{\prime}$ and $3^{\prime}$ noncoding region (NCR). The $5^{\prime}$ NCR contains the internal ribosome entry site that initiates the translation of the HCV genome into a single polyprotein; ${ }^{2}$ the $3^{\prime}$ NCR is required for efficient HCV RNA replication, ${ }^{3}$ as it has a specific tripartite structure: a variable region that is important for efficient RNA replication; a poly (U/UC) tract of variable length; and a highly conserved $X$ tail. ${ }^{4-6}$ Studies have demonstrated that the conserved elements in the $3^{\prime}$ NCR, including a minimal poly(U) tract of about 25 bases, are essential for HCV replication in cell culture and in vivo. ${ }^{7-10}$ Although the detailed mechanisms by which the $3^{\prime}$ NCR elements act on RNA replication are not clear, it is likely that binding of one or more viral or host

Keywords: HCV; Innate immunity; Interferon; miRNA; Treatment.

Abbreviations: HCV, hepatitis C virus; DLC, deleted in liver cancer; GAP, GTPase activating protein; IFN, interferon; ISRE, interferon-stimulated response element; miRNA, microRNA; NCR, noncoding region; pre-miRNA, precursor microRNA; RIG, retinoic acid-inducible gene; SVR, sustained virologic response; TLR, toll-like receptor Received: 17 August 2013; Revised: 15 October 2013; Accepted: 16 October 2013

DOI of original article: 10.14218/JCTH.2013.00012.

Correspondence to: Dr. Limin Chen, Institute of Blood Transfusion, Chinese Academy of Medical Sciences and Peking Union Medical College, Chengdu, Sichuan 610052 and Toronto General Research Institute, University of Toronto, Toronto, ON, Canada. Tel: +86-28-61648530, E-mail: limin.chen@utoronto.ca proteins to this RNA structure is necessary to establish the replication complex. ${ }^{11}$ The open reading frame encodes a polyprotein precursor of about 3000 amino acids that is cleaved by host and viral proteases into three structural proteins (core, E1, and E2) and seven nonstructural proteins (p7, NS2, NS3, NS4A, NS4B, NS5A, and NS5B) (Fig. 1). ${ }^{3,12}$ $\mathrm{HCV}$ has six major genotypes and each genotype contains numerous variants. ${ }^{13}$ Each genotype has its own epidemiologic characteristics. Genotypes 1-3 have worldwide distribution. Genotype 1 is predominant in America ${ }^{14,15}$ and Europe, ${ }^{16,17}$ followed by genotypes 2 and $3 ;^{18,19}$ and genotype 4 is the most common genotype in Africa and the Middle East, ${ }^{20-22}$ and is often seen among immigrants or indigenous injection drug users in North America and Europe. ${ }^{23,24}$ Genotype 5 is mainly distributed in South Africa ${ }^{25}$ and genotype 6 has been found primarily in Asia. ${ }^{26-28}$

$\mathrm{HCV}$ infection is a major cause of liver disease, with a high possibility of chronic infection. If left untreated, chronic HCV infection frequently results in progressive fibrosis, cirrhosis, and an increased risk of hepatocellular carcinoma. ${ }^{2}$ The most recent report from the World Health Organization estimates that about 150 million people worldwide are chronically infected with hepatitis C virus (www.who.int). Unfortunately, there is still no effective vaccine for HCV. ${ }^{29}$ To date, the standard of care for chronic HCV infection in most countries is combination therapy with pegylated interferon (IFN) $\alpha$ and ribavirin. However, the sustained virologic response (SVR) rate is just $40-50 \%$ in patients infected with HCV genotype 1 and $80 \%$ in patients infected with HCV genotypes 2 or $3^{2,30,31}$ Since 2011, treatment for HCV infection has been improved by adding one of the HCV nonstructural protein NS3/4A serine protease inhibitors, telaprevir or boceprevir, to pegylated IFN $\alpha$ and ribavirin. ${ }^{32}$ This regimen improves the SVR to $75 \%$ in patients infected with HCV genotype $1 .{ }^{33} \mathrm{NS} 3 / 4 \mathrm{~A}$ serine protease plays at least two roles in the HCV life cycle. First, it is responsible for cleaving the HCV polypeptide into individual viral proteins; it is essential for viral replication and virion assembly. $32,34,35$ Second, NS3/4A protease inhibits the innate immune response to facilitate $\mathrm{HCV}$ persistence. Therefore, NS3/4A protease is a good target for inhibitors that inhibit HCV replication and restore the host's innate immunity. Following the successful determination of the crystal structure of NS3/ 4A protease, small molecules specifically binding to the catalytic site of the NS3/4A protease were developed ${ }^{34}$ and two protease inhibitors, telaprevir and boceprevir, are now used to treat HCV infection in some countries. Although protease inhibitor-based therapy significantly improves the SVR, ${ }^{32,34}$ the high cost, severe adverse events, and rapid 


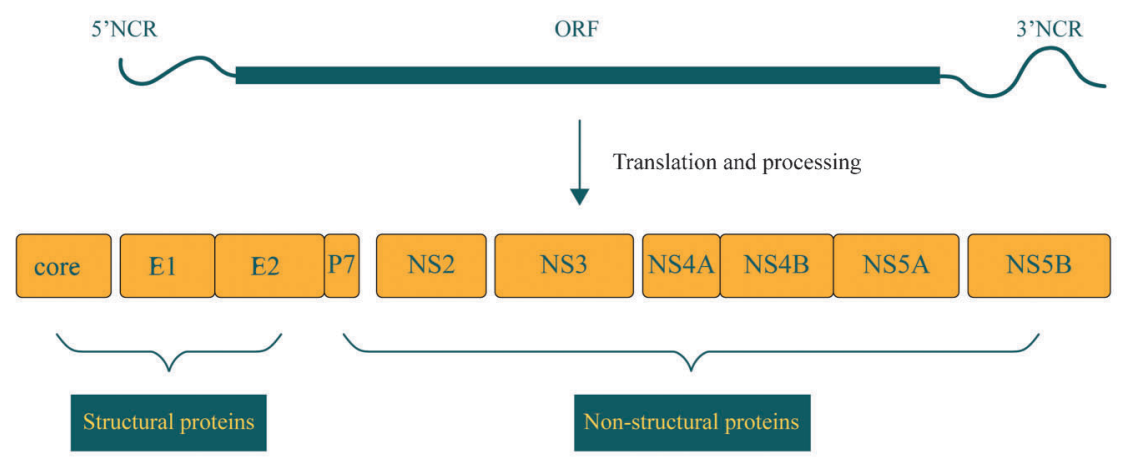

Fig. 1. The hepatitis C virus (HCV) genome and polyprotein. The HCV genome contains a single open reading frame that encodes a polyprotein that is cleaved by viral and host proteases to generate three structural and seven nonstructural proteins. Adapted from Georgel et al. ${ }^{3}$ and Rice $^{12}$

emergence of resistance mutations associated with these drugs limit their use in the developing countries where treatment is needed most. ${ }^{34}$ Therefore, there is a pressing need to identify new treatment options that are cost- and clinically effective for all HCV genotypes.

\section{MicroRNA: synthesis and functions}

MicroRNAs (miRNAs) belong to a noncoding gene family involved in eukaryotic posttranscriptional gene regulation. ${ }^{36-}$ 39 Transcription of miRNA genes forms primary transcripts (pri-miRNAs) that usually contain a hairpin structure. The stem-loop structure is then cleaved by an RNaseIII-like enzyme called drosha, together with its binding partner DGCR8 (DiGeorge syndrome critical region 8), to yield precursor miRNAs (pre-miRNAs) that are subsequently transferred from the nucleus to the cytoplasm with the help of exportin-5. In the cytoplasm, pre-miRNAs are processed by dicer RNA polymerase III into a duplex structure, from which one strand is separated and functions as the guide strand (functional strand) to be loaded together with Argonaute proteins into an RNA-induced silencing complex that recognizes and binds to the target mRNA. The other strand is degraded and nonfunctional (Fig. 2). ${ }^{36,40-44}$ MiRNA exerts its function by degrading the target mRNA (if the miRNA has perfect base pairing with its target mRNA) or inhibiting mRNA translation (if there is only partial pairing). ${ }^{45-47}$

The human genome encodes more than 1500 miRNAs (www.mirbase.org, released January 2012). Each miRNA can regulate numerous target genes and each mRNA is likely to be regulated by several miRNAs. ${ }^{48,49}$ The interaction of miRNAs and their target mRNAs results in a complex network that is involved in almost every cell process, including development, differentiation, proliferation, death, disease pathology, and antiviral defence. ${ }^{50-53}$ Most recently, increasing evidence suggests that cellular miRNAs and other components of the miRNA pathway can interact with viruses at multiple levels to influence viral replication. ${ }^{54,55}$ In this review, we summarize the miRNAs involved in $\mathrm{HCV}$ infection and their proposed connection with antiviral innate immunity.

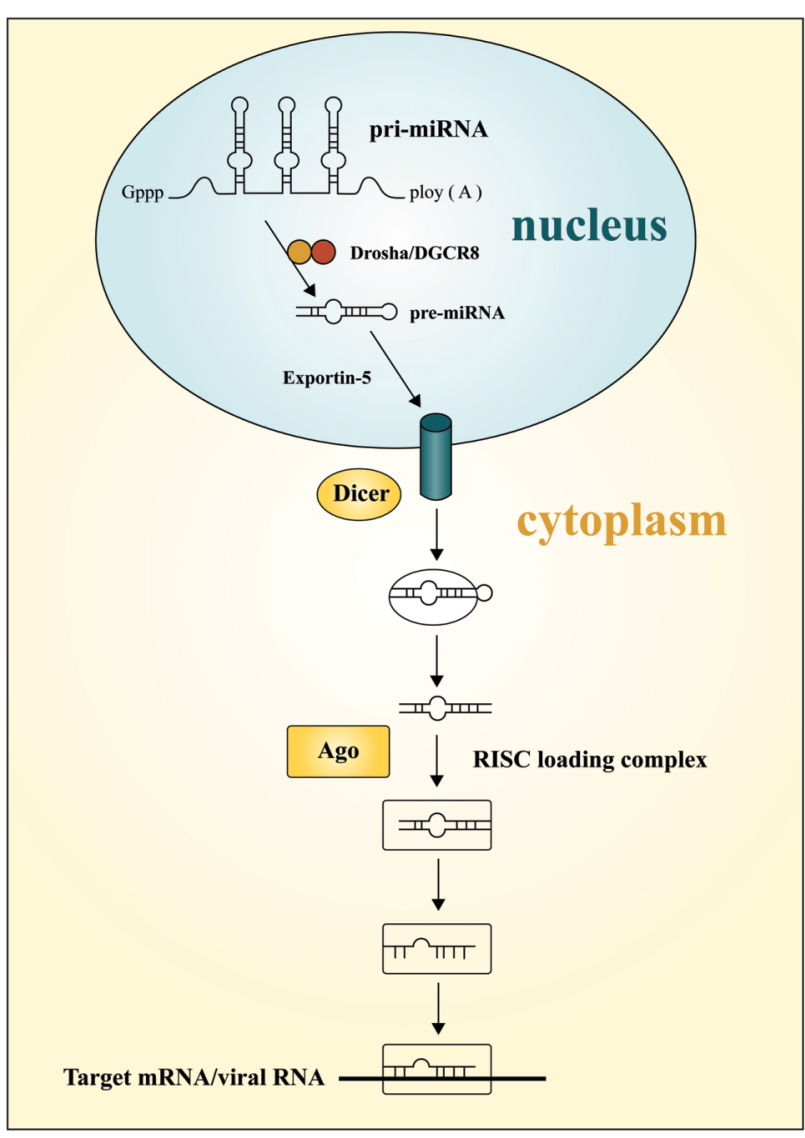

Fig. 2. The biogenesis of miRnA. Primary-miRnA (pri-miRnA) is processed by a drosha-DGCR8 microprocessor complex and forms a 70-100 nucleotide hairpin precursor (pre-miRNA). The pre-miRNA is transported from the nucleus to the cytoplasm by exportin -5 and cleaved by dicer into mature miRNA. Mature miRNA is loaded into an Argonaute (Ago) protein, where one strand of miRNA duplex is discarded. The retained strand mediates target selection by base pairing between miRNA and the 3 untranslated region of the target mRNA. Adapted from Bartel, ${ }^{36}$ Broderick and Zamore, ${ }^{40}$ Winter et al, ${ }^{41} \mathrm{Kim},{ }^{42}$ Thibault and Wilson, ${ }^{43}$ and Haasnoot and Berkhout ${ }^{44}$ 


\section{MiRNA and the innate immune response}

Innate immunity is the host's first line of defense against invading microbial pathogens. Type I IFN is a major player in the innate immune response, and is induced through pathways mediated by two distinct pathogen-associated molecular-pattern receptors: toll-like receptors (TLRs) and retinoic acid-inducible gene I (RIG-I)/melanoma differentiationassociated gene 5 . The miRNAs miR-155 and miR-146a/b have been shown to be involved in these pathways. ${ }^{56}$ The potential target genes of miR-146a, such as interleukin-1 receptor-associated kinase 1 and 2, TNF receptor-associated factor 6, RIG-I, and IFN-regulatory factor 5, play a critical role in these type I induction pathways. ${ }^{57}$ Inducible expression of miR-155 has been observed in both bacterial and viral infections, and may act as a negative feedback regulator of the TLR pathway to dampen the innate immune response. ${ }^{58-60}$ In addition, miR-155 has been shown to be involved in carcinogenesis. ${ }^{61-64}$ Two oncogenic viruses, Kaposi's sarcoma-associated herpesvirus and the avian $\alpha$-herpesvirus Marek's disease virus type 1 , can encode miR-155 mimics miR-K12-11 and miR-M4, respectively. ${ }^{65-67}$ Both of the virus-encoded miRNAs share high sequence similarity with miR-155 and therefore function as an ortholog of cellular miR155. ${ }^{65-68}$ Although numerous lines of evidence point to the fact that more and more miRNAs are involved in host innate immunity either directly or indirectly, $53,55,69,70$ we are just at the very start of understanding the diverse roles of miRNA in regulating host immunity. More studies are needed to understand how cellular miRNAs interact with the antiviral innate immune response. Data from these studies may shed light on potential therapeutic targets.

\section{MiRNA and HCV infection}

Recent studies demonstrate that miRNAs can affect the replication of some pathogenic viruses. MiRNAs have diverse roles in HCV infection. Some cellular miRNAs inhibit HCV RNA replication, while others stimulate its replication.

\section{MiRNAs that suppress HCV replication}

Type I IFN plays an irreplaceable role in anti-HCV defense. Quite interestingly, as the key player in HCV therapy, IFN $\beta$ treatment can rapidly modulate the expression of numerous cellular miRNAs. ${ }^{71}$ Using microarray technology, Pedersen et al. analyzed the expression of cellular miRNAs in IFNstimulated cells and found that the expression levels of about 30 miRNAs were altered (increased or decreased). ${ }^{71}$ Furthermore, they analyzed the sequence of these miRNAs and HCV genomic RNA and identified eight IFN $\beta$-induced miRNAs (miR-1, -30,-128, -196, -296, -351, -431, and -448) that matched with HCV genome perfectly. Functional assays showed that overexpression of these miRNAs by transfection of the miRNA mimics reproduced the antiviral effect of IFN $\beta$ in Huh7 cells, while their neutralization with anti-miRNAs dampened the antiviral effects of IFN $\beta$ against HCV. ${ }^{71}$ Similarly, another independent study reported that miR-196 inhibited HCV RNA replication in HCV replicon cells (genotypes $1 \mathrm{~b}$ and $2 \mathrm{a}){ }^{72}$ Both studies illustrated that one of the mechanisms for IFN inhibition of HCV RNA replication is probably the induction of cellular miRNAs that can directly degrade HCV RNA. In addition to the IFN-inducible miRNAs described above, there are many other miRNAs that can also inhibit HCV replication. For example, the overexpression of miR-199a has been reported to suppress HCV RNA replication, while inhibition by a specific antisense oligonucleotide upregulated viral replication in two cell lines bearing the replicons HCV-1b or $-2 a .^{73}$

In addition to the direct inhibition, some miRNAs inhibit HCV RNA replication indirectly by activating the IFN pathway. For example, miR-130a has been shown to be able to inhibit $\mathrm{HCV}$ replication in both replicon (genotype $1 \mathrm{~b}$ ) and JFH1 infectious models. Li et al. transfected miR-130a mimic into cultured Huh7.5.1 cells stably expressing an HCV genome and found that replication of HCV RNA was significantly inhibited. ${ }^{74}$ Further studies showed that the expression levels of type I IFNs (IFN $\alpha$ and IFN $\beta$ ) were significantly increased. As Huh7.5.1 cells are deficient in both TLR3 and RIG-I, two important mediators of type I IFN induction, these cells cannot recognize $\mathrm{HCV}$ infection and, as a result, almost no type I IFNs are produced following virus infection. These results imply that miR-130a may inhibit HCV replication indirectly, probably by restoring the host innate immune response in TLR3- and RIG-I-deficient cells. ${ }^{74}$ However, other investigators have demonstrated that $\mathrm{HCV}$ infection upregulates miR-130a, and that interferon-induced transmembrane protein 1 (IFITM1) is a direct target for this miRNA: knockdown of miR-130a enhanced IFITM1 expression and reduced HCV replication. ${ }^{75}$ This study demonstrated that HCV evades innate immune attack by decreasing antiviral IFITM1 expression through miR-130a. Since Li et al found miR-130a upregulated the IFN expression, the expression of the IFNstimulated gene IFITM1 should increase (although not tested in their study). These two studies reached seemingly contradictory results, which may indicate that miR-130a has more than one target, and the interaction of this miRNA with the host innate immune system is complex. In any case, the interaction between miR-130a and the host innate immune system deserves further study.

\section{MiRNAs that stimulate HCV replication}

MiR-122 is the most abundant liver-specific miRNA, accounting for around $70 \%$ of the total miRNA content in mammalian liver tissue. ${ }^{76}$ It is undetectable in other tissues in mice. ${ }^{76}$ Studies have demonstrated that miR-122 acts as a regulator of fatty-acid metabolism in mouse liver, ${ }^{77}$ and reduced miR122 levels are associated with hepatocellular carcinoma. ${ }^{78-81}$ In addition, of all the miRNAs, miR-122 is unique in its stimulatory, not inhibitory, role in HCV replication. ${ }^{82}$ The discovery that miR-122 is required for HCV replication linked a host miRNA to a human infectious disease for the first time. $^{83}$ The role of miR-122 in HCV replication was first reported by Jopling et al. in $2005 .^{82}$ They sequestrated miR122 with antisense oligonucleotides and found that HCV RNA accumulation decreased. ${ }^{82}$ In addition, they also identified two target sites in the $\mathrm{HCV} 5^{\prime}$ untranslated region that are necessary for HCV replication. Since then, a large number of elegant studies have been performed to show that the interaction between miR-122 and viral $5^{\prime}$ NCR is essential to promote HCV replication. ${ }^{84-88}$

The role of miR-122 as an important, possibly essential, host factor for HCV production makes it an attractive candidate for antiviral therapy. Modified antisense agents and small-molecule inhibitors have been developed as potential new lead compounds for drug discovery. ${ }^{89}$ Most recently, treatment with miravirsen (SPC3649) efficiently 
suppressed HCV genotype $1 \mathrm{a}$ and $1 \mathrm{~b}$ infections in chimpanzees, with no evidence of viral resistance or side effects. ${ }^{90}$ Miravirsen, a locked nucleic acid-modified DNA phosphorothioate antisense oligonucleotide of miR-122, has also been trialed in patients with chronic HCV genotype 1, with the results showing a dose-dependent reduction in HCV RNA levels without the occurrence of viral resistance. ${ }^{91}$

In addition to targeting HCV RNA directly, Yoshikawa et al. found that overexpression of miR-122 suppresses the activity of IFN-stimulated response element (ISRE) while significantly silencing miR-122-enhanced IFN-induced ISRE activity. ${ }^{92}$ ISREs are specific nucleotide sequences located in the promoters of IFN-stimulated genes that encode antiviral proteins and can induce transcription of these genes by binding with IFN-stimulated gene factor $3 .^{93}$ Furthermore, Yoshikawa et al. found that silencing miR-122 decreased the expression of suppressor of cytokine signaling, a negative regulator of IFN signaling, in mouse liver, leading to increased IFN anti-HCV activity. ${ }^{92}$ This study indicates that the anti-HCV effect of miR-122 might also be mediated by decreasing the expression of antiviral proteins or increasing negative regulators of cytokine production.

Most recently, it has been reported that miR-141, which can be induced by HCV infection, may also be necessary for efficient HCV replication. ${ }^{94}$ MiR-141 belongs to the miR-200 family, which is believed to play an essential role in tumor suppression by inhibiting epithelial-mesenchymal transition, the initiating step of metastasis. ${ }^{95,96}$ Banaudha et al. transfected an miR-141 mimic or antagonist into HCV1ainfected hepatocytes to increase or deplete intracellular miR141 expression, respectively. ${ }^{94}$ The results showed that overexpression of miR-141 enhanced HCV replication, while depletion of miR-141 inhibited virus replication. Meanwhile, they identified DLC-1 (deleted in liver cancer 1 ) as one of the target genes. ${ }^{94}$ Increasing miR-141 decreased DLC-1 protein levels without a parallel decrease in DLC-1 mRNA levels, suggesting that miR-141 primarily targets translational inhibition of DLC-1. ${ }^{94}$ DLC-1 encodes a member of the RhoGTPase activating protein (GAP) family of proteins. The RhoGAP proteins can specifically catalyze the conversion of the active GTP-bound RhoA protein into the inactive GDP-bound protein. ${ }^{97,98}$ Active RhoA protein is required for Ras-mediated tumorigenic transformation, ${ }^{99}$ and Rho-GAPs may therefore act as important negative regulators in human carcinogenesis. In hepatocellular carcinoma, homozygous deletion or loss of DLC-1 mRNA expression usually occurs in vivo and in vitro. ${ }^{98,100}$ In addition, restoration of DLC-1 in hepatoma cell lines lacking DLC -1 results in reduced cell proliferation as well as reduced metastatic activity. ${ }^{100}$ Since HCV-infected cells express miR-141, and its overexpression significantly suppresses DLC- 1 expression, ${ }^{94}$ the results indicate the presence of a novel mechanism of HCV infection-associated miRNAmediated regulation of a tumor suppressor protein, which is worth further exploration.

MiRNAs involved in $\mathrm{HCV}$ infection and their interactions with the innate immune system are summarized in Table 1.

\section{Future directions}

MiRNAs are endogenous, short, noncoding RNAs that function at the posttranscriptional (mRNA) level through mRNA degradation or inhibition of translation. Host miRNAs play various important roles in many cellular processes, including host innate immunity and cell defense. Increasing lines of evidence suggest that many miRNAs are involved in the viral life cycle. For HCV, miRNAs can either stimulate or inhibit viral RNA replication through distinct mechanisms. In the past few years, many studies have focused on identifying differentially expressed miRNAs before and after HCV infection. Identifying their target mRNAs remains a great challenge, as a complex network of interaction exists between miRNAs and mRNAs. Although high-throughput screening methods such as genome-wide association studies and microarrays may reveal the complicated network of regulation and eventually identify targets for intervention, functional studies will have to be performed to validate these targets experimentally.

Remarkably, the advent of anti-miR-122 drugs is opening a new era for HCV therapy. Although many miRNAs have been identified in vitro, and the function of many of these has not been verified in vivo, miRNAs have great potential as therapeutic targets for viral infection, in addition to many other diseases.

\section{Conflict of interest}

None.

\section{Author contributions}

Designing the outline of this review (LMC), drafting the manuscript (XQD); collecting related information and editing the manuscript ( $S L L, Y J L, B L, P B Z, C H Y$ ).

Table 1. Summary of miRNAs involved in HCV infection and their interactions with the innate immune system

\begin{tabular}{llll}
\hline miRNA & Effect on HCV infection & Link to innate immunity & Reference \\
\hline miR-130a & Inhibits HCV replication in vitro & Restores the IFN signaling pathway & 74 \\
& Benefits HCV infection in vitro & Targets interferon-induced transmembrane proteins & 75 \\
miR-196 & Inhibits HCV expression in vitro & $\begin{array}{l}\text { Targets Bach1, which is involved in the inflammatory } \\
\text { response }\end{array}$ & 71,72 \\
miR-199a & Inhibits HCV replication in vitro & Independent of IFN signaling pathway & 73 \\
miR-122 & Promotes HCV replication & Decreases IFN-induced ISRE activity & 92 \\
& Positively regulates the HCV life cycle & Targets the HCV genome directly (independent of the & 82,86 \\
miR-141 & Required for HCV replication in vitro & IFN signaling pathway) & \\
\hline
\end{tabular}

HCV, hepatitis C virus; IFN, interferon; ISRE, interferon-stimulated response element; miRNA, microRNA 


\section{References}

[1] Takamizawa A, Mori C, Fuke I, Manabe S, Murakami S, Fujita J, et al. Structure and organization of the hepatitis $C$ virus genome isolated from human carriers. J Virol 1991;65:1105-1013.

[2] Kim CW, Chang KM. Hepatitis C virus: virology and life cycle. Clin Mo Hepatol 2013;19:17-25.

[3] Georgel P, Schuster C, Zeisel MB, Stoll-Keller F, Berg T, Bahram S, et al. Virus-host interactions in hepatitis $C$ virus infection: implications for molecular pathogenesis and antiviral strategies. Trends Mol Med 2010; 16:277-286.

[4] Blight KJ, Rice CM. Secondary structure determination of the conserved 98base sequence at the $3^{\prime}$ terminus of hepatitis $C$ virus genome RNA. J Viro 1997;71:7345-7352

[5] Kolykhalov AA, Feinstone SM, Rice CM. Identification of a highly conserved sequence element at the $3^{\prime}$ terminus of hepatitis $C$ virus genome RNA. J Virol 1996;70:3363-3371.

[6] Tanaka T, Kato N, Cho MJ, Shimotohno K. A novel sequence found at the 3'terminus of hepatitis C virus genome. Biochem Biophys Res Commun 1995; 215:744-749.

[7] Yanagi M, St Claire M, Emerson SU, Purcell RH, Bukh J. In vivo analysis of the $3^{\prime}$ untranslated region of the hepatitis $C$ virus after in vitro mutagenesis of an infectious cDNA clone. Proc Natl Acad Sci USA 1999;96:2291-2295.

[8] Yi M, Lemon SM. 3' nontranslated RNA signals required for replication of hepatitis C virus RNA. J Virol 2003;77:3557-3568.

[9] Friebe P, Bartenschlager R. Genetic analysis of sequences in the 3 nontranslated region of hepatitis $C$ virus that are important for RNA replication. J Virol 2002;76:5326-5338.

[10] Kolykhalov AA, Mihalik K, Feinstone SM, Rice CM. Hepatitis C virus-encoded enzymatic activities and conserved RNA elements in the $3^{\prime}$ nontranslated region are essential for virus replication in vivo. J Virol 2000;74:20462051.

[11] You S, Rice CM. 3' RNA elements in hepatitis C virus replication: kissing partners and long poly(U). J Virol 2008;82:184-195.

[12] Rice CM. New insights into HCV replication: potential antiviral targets. Top Antivir Med 2011;19:117-120.

[13] Simmonds P, Bukh J, Combet C, Deléage G, Enomoto N, Feinstone S, et al. Consensus proposals for a unified system of nomenclature of hepatitis $C$ virus genotypes. Hepatology 2005;42:962-973.

[14] Nainan OV, Alter MJ, Kruszon-Moran D, Gao FX, Xia G, McQuillan G, et al. Hepatitis $C$ virus genotypes and viral concentrations in participants of a general population survey in the United States. Gastroenterology 2006; $131: 478-484$

[15] Rustgi VK. The epidemiology of hepatitis C infection in the United States. J Gastroenterol 2007;42:513-521.

[16] Dusheiko G, Schmilovitz-Weiss H, Brown D, McOmish F, Yap PL, Sherlock S, et al. Hepatitis $C$ virus genotypes: an investigation of type-specific differences in geographic origin and disease. Hepatology 1994;19:13-18.

[17] Nousbaum JB, Pol S, Nalpas B, Landais P, Berthelot P, Bréchot C. Hepatitis C virus type 1b (II) infection in France and Italy. Collaborative Study Group. Ann Intern Med 1995;122:161-168.

[18] McOmish F, Chan SW, Dow BC, Gillon J, Frame WD, Crawford RJ, et al. Detection of three types of hepatitis $C$ virus in blood donors: investigation of type-specific differences in serologic reactivity and rate of alanine aminotransferase abnormalities. Transfusion 1993;33:7-13.

[19] Viazov S, Kuzin S, Paladi N, Tchernovetsky M, Isaeva E, Mazhul L, et al. Hepatitis $C$ virus genotypes in different regions of the former Soviet Union (Russia, Belarus, Moldova, and Uzbekistan). J Med Virol 1997;53:36-40.

[20] Ramia S, Eid-Fares J. Distribution of hepatitis C virus genotypes in the Middle East. Int J Infect Dis 2006;10:272-277.

[21] Ray SC, Arthur RR, Carella A, Bukh J, Thomas DL. Genetic epidemiology of hepatitis C virus throughout egypt. J Infect Dis 2000;182:698-707.

[22] Xu LZ, Larzul D, Delaporte E, Bréchot C, Kremsdorf D. Hepatitis C virus genotype 4 is highly prevalent in central Africa (Gabon). J Gen Virol 1994; 75:2393-1298.

[23] Lyra AC, Ramrakhiani S, Bacon BR, Di Bisceglie AM. Infection with hepatitis C virus genotype 4 in the United States. J Clin Gastroenterol 2004;38:6871.

[24] Matera G, Lamberti A, Quirino A, Focà D, Giancotti A, Barreca GS, et al. Changes in the prevalence of hepatitis $C$ virus (HCV) genotype 4 in Calabria, Southern Italy. Diagn Microbiol Infect Dis 2002;42:169-173.

[25] Smuts HE, Kannemeyer J. Genotyping of hepatitis C virus in South Africa. J Clin Microbiol 1995;33:1679-1681.

[26] Simmonds P, Mellor J, Sakuldamrongpanich T, Nuchaprayoon C, Tanprasert $\mathrm{S}$, Holmes EC, et al. Evolutionary analysis of variants of hepatitis $\mathrm{C}$ virus found in South-East Asia: comparison with classifications based upon sequence similarity. J Gen Virol 1996;77:3013-3024.
[27] Mellor ], Walsh EA, Prescott LE, Jarvis LM, Davidson F, Yap PL, et al. Survey of type 6 group variants of hepatitis $C$ virus in Southeast Asia by using a core-based genotyping assay. J Clin Microbiol 1996;34:417-423.

[28] Lu L, Nakano T, He Y, Fu Y, Hagedorn CH, Robertson BH. Hepatitis C virus genotype distribution in China: predominance of closely related subtype $1 \mathrm{~b}$ isolates and existence of new genotype 6 variants. J Med Virol 2005;75: 538-549.

[29] Mohd Hanafiah K, Groeger J, Flaxman AD, Wiersma ST, Global epidemiology of hepatitis $\mathrm{C}$ virus infection: new estimates of age-specific antibody to $\mathrm{HCV}$ seroprevalence. Hepatology 2013;57:1333-1342.

[30] Fried MW, Shiffman ML, Reddy KR, Smith C, Marinos G, Gonçales FL Jr, et al. Peginterferon alfa-2a plus ribavirin for chronic hepatitis $C$ virus infection. N Engl J Med 2002;347:975-982.

[31] Hadziyannis SJ, Sette H Jr, Morgan TR, Balan V, Diago M, Marcellin P, et al. Peginterferon-alpha2a and ribavirin combination therapy in chronic hepatitis C: a randomized study of treatment duration and ribavirin dose. Ann Intern Med 2004;140:346-355.

[32] Ghany MG, Nelson DR, Strader DB, Thomas DL, Seeff LB; American Association for Study of Liver Diseases. An update on treatment of genotype 1 chronic hepatitis $C$ virus infection: 2011 practice guideline by the American Association for the Study of Liver Diseases. Hepatology 2011 54:1433-1444

[33] Buhler S, Bartenschlager R. New targets for antiviral therapy of chronic hepatitis C. Liver Int 2012;(Suppl 1):9-16.

[34] Cartwright EJ, Miller L. Novel drugs in the management of difficult-to-treat hepatitis C genotypes. Hepatic Medicine: Evidence and Research 2013;5: 53-61.

[35] Shiryaev SA, Thomsen ER, Cieplak P, Chudin E, Cheltsov AV, Chee MS, et al. New details of HCV NS3/4A proteinase functionality revealed by a highthroughput cleavage assay. PLoS One 2012;7:e35759.

[36] Bartel DP. MicroRNAs: genomics, biogenesis, mechanism, and function. Cell 2004; 116:281-297

[37] Tomari Y, Zamore PD. Perspective: machines for RNAi. Genes Dev 2005; 19: 517-529.

[38] Lagos-Quintana M, Rauhut R, Lendeckel W, Tuschl T. Identification of novel genes coding for small expressed RNAs. Science 2001;294:853-858.

[39] Ambros V, Bartel B, Bartel DP, Burge CB, Carrington JC, Chen X, et al. A uniform system for microRNA annotation. RNA 2003;9:277-279.

[40] Broderick JA, Zamore PD. MicroRNA therapeutics. Gene Ther 2011;18: $1104-1110$

[41] Winter J, Jung S, Keller S, Gregory RI, Diederichs S. Many roads to maturity: microRNA biogenesis pathways and their regulation. Nat Cell Biol 2009;11:228-234.

[42] Kim VN. MicroRNA biogenesis: coordinated cropping and dicing. Nat Rev Mol Cell Biol 2005;6:376-385.

[43] Thibault PA, Wilson JA. Targeting miRNAs to treat hepatitis C virus infections and liver pathology: inhibiting the virus and altering the host. Pharmacol Res 2013;75:48-59.

[44] Haasnoot J, Berkhout B. RNAi and cellular miRNAs in infections by mammalian viruses. Methods Mol Biol 2011;721:23-41.

[45] Hutvagner G, Zamore PD. A microRNA in a multiple-turnover RNAi enzyme complex. Science 2002;297:2056-2060.

[46] Yekta S, Shih IH, Bartel DP. MicroRNA-directed cleavage of HOXB8 mRNA. Science 2004;304:594-596.

[47] Song JJ, Smith SK, Hannon GJ, Joshua-Tor L. Crystal structure of Argonaute and its implications for RISC slicer activity. Science 2004;305:1434-1437.

[48] Ryazansky SS, Gvozdev VA. Small RNAs and cancerogenesis. Biochemistry (Mosc) 2008;73:514-527.

[49] Lewis BP, Shih IH, Jones-Rhoades MW, Bartel DP, Burge CB. Prediction of mammalian microRNA targets. Cell 2003;115:787-798.

[50] Stefani G, Slack FJ. Small non-coding RNAs in animal development. Nat Rev Mol Cell Biol 2008;9:219-230.

[51] Foshay KM, Gallicano GI. Small RNAs, big potential: the role of MicroRNAs in stem cell function. Curr Stem Cell Res Ther 2007;2:264-271.

[52] Blakaj A, Lin H. Piecing together the mosaic of early mammalian development through microRNAs. J Biol Chem 2008;283:9505-9508.

[53] Zhou R, O'Hara SP, Chen XM. MicroRNA regulation of innate immune responses in epithelial cells. Cell Mol Immunol 2011;8:371-379.

[54] Gottwein E, Cullen BR. Viral and cellular microRNAs as determinants of viral pathogenesis and immunity. Cell Host Microbe 2008;3:375-387.

[55] Witwer KW, Sisk JM, Gama L, Clements JE. MicroRNA regulation of IFN-beta protein expression: rapid and sensitive modulation of the innate immune response. J Immunol 2010;184:2369-2376.

[56] Bala S, Marcos M, Szabo G. Emerging role of microRNAs in liver diseases. World J Gastroenterol 2009;15:5633-5640.

[57] Li L, Chen XP, Li YJ. MicroRNA-146a and human disease. Scand J Immuno 2010;71:227-231.

[58] David M. Interferons and microRNAs. J Interferon Cytokine Res 2010;30: 825-828 
[59] O'Connell RM, Taganov KD, Boldin MP, Cheng G, Baltimore D. MicroRNA-155 is induced during the macrophage inflammatory response. Proc Natl Acad Sci U S A 2007; 104:1604-1609.

[60] Tili E, Michaille J], Cimino A, Costinean S, Dumitru CD, Adair B, et al. Modulation of miR-155 and miR-125b levels following lipopolysaccharide/ TNF-alpha stimulation and their possible roles in regulating the response to endotoxin shock. J Immunol 2007;179:5082-5089.

[61] Jiang S, Zhang HW, Lu MH, He XH, Li Y, Gu H, et al. MicroRNA-155 functions as an OncomiR in breast cancer by targeting the suppressor of cytokine signaling 1 gene. Cancer Res 2010;70:3119-3127.

[62] Chang S, Wang RH, Akagi K, Kim KA, Martin BK, Cavallone L, et al. Tumor suppressor BRCA1 epigenetically controls oncogenic microRNA-155. Nat Med 2011;17:1275-1282.

[63] Xiang $X$, Zhuang $X$, Ju S, Zhang S, Jiang $H$, Mu J, et al. miR-155 promotes macroscopic tumor formation yet inhibits tumor dissemination from mammary fat pads to the lung by preventing EMT. Oncogene 2011;30: 3440-3453.

[64] Saito Y, Suzuki H, Tsugawa H, Imaeda H, Matsuzaki J, Hirata K, et al. Overexpression of miR-142-5p and miR-155 in gastric mucosa-associated lymphoid tissue (MALT) lymphoma resistant to Helicobacter pylori eradication. PLoS One 2012;7:e47396.

[65] Skalsky RL, Samols MA, Plaisance KB, Boss IW, Riva A, Lopez MC, et al. Kaposi's sarcoma-associated herpesvirus encodes an ortholog of miR-155. J Virol 2007; 81:12836-12845.

[66] Gottwein E, Mukherjee N, Sachse C, Frenzel C, Majoros WH, Chi JT, et al. A viral microRNA functions as an orthologue of cellular miR-155. Nature 2007;450:1096-1099.

[67] Zhao Y, Xu H, Yao Y, Smith LP, Kgosana L, Green J, et al. Critical role of the virus-encoded microRNA-155 ortholog in the induction of Marek's disease lymphomas. PLoS Pathog 2011;7:e1001305.

[68] Zhao Y, Yao Y, Xu H, Lambeth L, Smith LP, Kgosana L, et al. A functional microRNA-155 ortholog encoded by the oncogenic Marek's disease virus. J Virol 2009;83:489-492.

[69] Lagos D, Pollara G, Henderson S, Gratrix F, Fabani M, Milne RS, et al. miR132 regulates antiviral innate immunity through suppression of the p300 transcriptional co-activator. Nat Cell Biol 2010;12:513-519.

[70] Sheedy FJ, Palsson-McDermott E, Hennessy EJ, Martin C, O'Leary J], Ruan $\mathrm{Q}$, et al. Negative regulation of TLR4 via targeting of the proinflammatory tumor suppressor PDCD4 by the microRNA miR-21. Nat Immunol 2010;11: 141-147.

[71] Pedersen IM, Cheng G, Wieland S, Volinia S, Croce CM, Chisari FV, et al. Interferon modulation of cellular microRNAs as an antiviral mechanism. Nature 2007;449:919-922.

[72] Hou W, Tian Q, Zheng J, Bonkovsky HL. MicroRNA-196 represses Bach1 protein and hepatitis $C$ virus gene expression in human hepatoma cells expressing hepatitis C viral proteins. Hepatology 2010;51:1494-1504.

[73] Murakami Y, Aly HH, Tajima A, Inoue I, Shimotohno K. Regulation of the hepatitis C virus genome replication by miR-199a. J Hepatol 2009;50:453460.

[74] Li S, Duan X, Li Y, et al. MicroRNA-130a inhibits HCV replication by restoring the innate immune response. J Viral Hepatit 2013 in press.

[75] Bhanja Chowdhury J, Shrivastava S, Steele R, Di Bisceglie AM, Ray R, Ray RB. Hepatitis $C$ virus infection modulates expression of interferon stimulatory gene IFITM1 by upregulating miR-130A. J Virol 2012;86:1022110225.

[76] Lagos-Quintana M, Rauhut R, Yalcin A, Meyer J, Lendeckel W, Tuschl T. Identification of tissue-specific microRNAs from mouse. Curr Biol 2002;12: 735-739.

[77] Esau C, Davis S, Murray SF, Yu XX, Pandey SK, Pear M, et al. miR-122 regulation of lipid metabolism revealed by in vivo antisense targeting. Cell Metab 2006;3:87-98

[78] Wu X, Wu S, Tong L, Luan T, Lin L, Lu S, et al. miR-122 affects the viability and apoptosis of hepatocellular carcinoma cells. Scand J Gastroenterol 2009;44:1332-1339.

[79] Tsai WC, Hsu PW, Lai TC, Chau GY, Lin CW, Chen CM, et al. MicroRNA-122, a tumor suppressor microRNA that regulates intrahepatic metastasis of hepatocellular carcinoma. Hepatology 2009;49:1571-1582.
[80] Chang J, Guo JT, Jiang D, Guo H, Taylor JM, Block TM. Liver-specific microRNA miR-122 enhances the replication of hepatitis $C$ virus in nonhepatic cells. J Virol 2008;82:8215-8223.

[81] Coulouarn C, Factor VM, Andersen JB, Durkin ME, Thorgeirsson SS. Loss of miR-122 expression in liver cancer correlates with suppression of the hepatic phenotype and gain of metastatic properties. Oncogene 2009;28: 3526-3536.

[82] Jopling $C L$, Yi M, Lancaster AM, Lemon SM, Sarnow P. Modulation of hepatitis C virus RNA abundance by a liver-specific MicroRNA. Science 2005;309:1577-1581.

[83] Adis International Limited. Summary of recent deal activity:Drug discovery technologies. Int J Pham Med 2006;20:393-399.

[84] Jopling CL, Schutz S, Sarnow P. Position-dependent function for a tandem microRNA miR-122-binding site located in the hepatitis $C$ virus RNA genome. Cell Host Microbe 2008;4:77-85.

[85] Jangra RK, Yi M, Lemon SM. Regulation of hepatitis C virus translation and infectious virus production by the microRNA miR-122. J Virol 2010;84: 6615-6625.

[86] Roberts AP, Lewis AP, Jopling CL. miR-122 activates hepatitis C virus translation by a specialized mechanism requiring particular RNA components. Nucleic Acids Res 2011;39:7716-7729.

[87] Norman KL, Sarnow P. Modulation of hepatitis C virus RNA abundance and the isoprenoid biosynthesis pathway by microRNA miR-122 involves distinct mechanisms. J Virol 2010;84:666-670.

[88] Randall G, Panis M, Cooper JD, Tellinghuisen TL, Sukhodolets KE, Pfeffer S, et al. Cellular cofactors affecting hepatitis $C$ virus infection and replication. Proc Natl Acad Sci USA 2007;104:12884-12889.

[89] Thomas M, Deiters A. MicroRNA miR-122 as a therapeutic target for oligonucleotides and small molecules. Curr Med Chem 2013;20:36293640.

[90] Lanford RE, Hildebrandt-Eriksen ES, Petri A, Persson R, Lindow M, Munk ME, et al. Therapeutic silencing of microRNA-122 in primates with chronic hepatitis C virus infection. Science 2010;327:198-201.

[91] Janssen HL, Reesink HW, Lawitz EJ, Zeuzem S, Rodriguez-Torres M, Patel K, et al. Treatment of HCV infection by targeting microRNA. N Engl J Med 2013;368:1685-1694

[92] Yoshikawa T, Takata A, Otsuka M, Kishikawa T, Kojima K, Yoshida H, et al. Silencing of microRNA-122 enhances interferon-alpha signaling in the liver through regulating SOCS3 promoter methylation. Sci Rep 2012;2:637.

[93] Kessler DS, Veals SA, Fu XY, Levy DE. Interferon-alpha regulates nuclear translocation and DNA-binding affinity of ISGF3, a multimeric transcriptional activator. Genes Dev 1990;4:1753-1765.

[94] Banaudha K, Kaliszewski M, Korolnek T, Florea L, Yeung ML, Jeang KT, et al. MicroRNA silencing of tumor suppressor DLC-1 promotes efficient hepatitis $C$ virus replication in primary human hepatocytes. Hepatology 2011;53: 53-61.

[95] Korpal M, Lee ES, Hu G, Kang Y. The miR-200 family inhibits epithelialmesenchymal transition and cancer cell migration by direct targeting of $\mathrm{E}$ cadherin transcriptional repressors ZEB1 and ZEB2. J Biol Chem 2008;283: 14910-14914.

[96] Korpal M, Kang $Y$. The emerging role of miR-200 family of microRNAs in epithelial-mesenchymal transition and cancer metastasis. RNA Biol 2008; 5:115-119.

[97] Yuan BZ, Jefferson AM, Baldwin KT, Thorgeirsson SS, Popescu NC, Reynolds SH. DLC-1 operates as a tumor suppressor gene in human non-small cell lung carcinomas. Oncogene 2004;23:1405-1411.

[98] Yuan BZ, Miller MJ, Keck CL, Zimonjic DB, Thorgeirsson SS, Popescu NC. Cloning, characterization, and chromosomal localization of a gene frequently deleted in human liver cancer (DLC-1) homologous to rat RhoGAP. Cancer Res 1998;58:2196-2199.

[99] Khosravi-Far R, Solski PA, Clark GJ, Kinch MS, Der C]. Activation of Rac1, RhoA, and mitogen-activated protein kinases is required for Ras transformation. Mol Cell Biol 1995; 15:6443-6453.

[100] Ng IO, Liang ZD, Cao L, Lee TK. DLC-1 is deleted in primary hepatocellular carcinoma and exerts inhibitory effects on the proliferation of hepatoma cell lines with deleted DLC-1. Cancer Res 2000;60:6581-6584. 